\title{
Informative indices of physical and functional state of young men during the process of adaptation to learning
}

\author{
Tulyakova O.V. ${ }^{1 \mathrm{ABCD}}$, Avdeeva M.S..$^{2 \mathrm{ABCD}}$ \\ ${ }^{1}$ Department of Students' Research Work, Vyatka State University, Russia \\ ${ }^{2}$ Department of Physical Education, Vyatka State University, Russia
}

Authors' Contribution:

A - Study design; B - Data collection; C - Statistical analysis; D - Manuscript Preparation; E - Funds Collection.

\begin{abstract}
Purpose: $\quad$ to determine indicators of physical development, physical readiness, functional condition of young men in the process of adaptation to learning.

Material: $\quad$ The students of university ( $n=78$, age 18-20 years) were examined. An examination was conducted at the beginning of the first and second years of study. It was studied 8 indexes and 5 indexes for physical development.

Results: $\quad$ it is established that during the first year of study there is an increase in: weight-growth indices; endurance factor; adaptive capacity; diastolic pressure; running record on $1000 \mathrm{~m}$. The vital capacity of the lungs decreased; life index; time of hanging on a bar.

Conclusions: indicators of students' adaptation to learning are suggested to be: body mass index (physical development index); running on $1000 \mathrm{~m}$ (the indicator of physical readiness); coefficient of endurance (indicator of functional state).

Keywords: $\quad$ students, adaptation, endurance, weight, strength.
\end{abstract}

\section{Introduction}

According to official statistics, about $30 \%$ of university graduates are professionally inapplicable because of poor health [1]. The revealed changes are connected with the way of life of modern students [2]. The risk factors for increasing body mass index (BMI) mention a high intake of sweet soda, enthusiasm for computer games [3], more frequent use of alcohol [3], transition to sedentary lifestyles [4], decrease in active movement and exercise [5], bad habits [6]. In addition to lifestyle, health of young men is influenced upon the following features: living in ecologically disadvantaged areas [7], educational process at the university [8]. It is shown that during the 1-3 courses of study among students is formed chronic emotional stress [9], increased the tension of the mechanisms of regulation of heart rhythm [10].

In the literature, there are data on the increase in the body weight of students [11]. After 1 semester students added about $1 \mathrm{~kg}$ of weight [12], during the year $-4,7 \mathrm{~kg}$ [5], for a year $-3 \mathrm{~kg}$, together with an increase in the body mass index (BMI) [4].

In other studies, it was found that in the first year the results of hand dynamometry and time of hanging on a bar [13], the results of hand dynamometry and jump in length from the place have changed [14]. It is proposed to use 5- and 15-minute run as indicators of aerobic capacity [9]. It is shown that muscle strength is not associated with academic achievement [15]. As informative indicators of students' health are considered both weight-for-height index and the results of Genchi and Ruffier tests [8].

One approach to assessing physical development is based on the compliance of the main indicators of physical development with age and sex standards.

\footnotetext{
(C) Tulyakova O.V., Avdeeva M.S., 2018

doi:10.15561/18189172.2018.0106
}

Another approach involves the use of indicator indexes of physical development, physical preparedness, and the functional state of students. Indicators are indexes, most vividly (in the form of statistically significant differences) reflecting the detected changes. Unfortunately, many of them are not unified. This makes it difficult to verify the results of the experiments. Therefore, the question arises of the formation of a set of indicator indexes.

Indicator indexes are important for assessing the functional state of the leading systems of the body and the adequacy of motor regimes [16]. As indicator indexes it is proposed to use: long jump [14], breath retention (Genchi test), heart rate variability [10], maximum oxygen consumption [17], Martinet-Kushelevsky test [16], results of hand dynamometry [11]. The literature data on the informativeness of the mass-growth index are contradictory [18]. In general, the presented data are fragmented, there is no systematic approach to determination of indicator indexes.

Among other ways to solve the problems of increasing the indicators of the physical and functional state of youth can be identified the following: pedagogical control and selection of adequate tests of physical fitness [19, 20]; optimization of physical activities [21, 22]; didactic patterns of the construction of education [23]; formation of positive attitude towards one's health $[24,25]$; motivation for successful education $[26,27]$; criteria for the effectiveness of the learning process $[28,29]$.

The authors used different approaches to increase the level of physical and functional state of students and young people. Such approaches can help students adapt to learning.

Adaptation of students to learning is closely related to the internal environment of the university. The conditions of the external environment are also an important factor 
in adaptation of students to learning. In studies of the influence of these factors on the students' learning and health indicators it is established: possibilities for increasing the motor activity of students [30, 31]; possibilities of adaptation to physical loads [32, 33]; influence of cardio training methods on power indicators of students [34]; opportunities for improving the functional state of students $[35,36]$; directions of the account of individual features of students' development [37, 38]; directions for improving the quality of life of young people [39-41]; possibilities of increasing endurance rates [42]; possibilities for correcting posture [43]; possibilities of social adaptation of students $[44,45]$.

The authors use various forms of presentation of indicators that are aimed at improving the health of students and youth. This allows students to more successfully adapt to university studies.

Hypothesis: in order to successfully solve the problem it is necessary to identify informative indicator indexes of adaptation to learning.

The purpose of the study is to determine the indicator indexes of physical development, physical preparedness, functional status of young men in the process of adaptation to learning.

\section{Material and methods}

Participants. The study was conducted at Vyatka State University (Kirov, Russia) with first and second year students (first and third semesters, September-October). 78 young men of full-time study were examined. The average age of first-year students was $18,51 \pm 0,10$ years (group 1) and 20,43 $\pm 0,12$ years in the second year of study (group 2). At the time of the study, no one complained of health problems. All students gave voluntary consent to participate in the survey.

Organization of the study. We studied 8 indexes and 5 indexes for physical development, 9 physical fitness indexes, 2 functional tests and 4 indexes and coefficients for the functional state.

We were examined from 52 to 73 students by different indicators from the group of 78 people.

To measure physical development were measured length $(\mathrm{cm})$, body weight $(\mathrm{kg})$, chest circumference (CC, $\mathrm{cm})$ [46] and weight-height indices were calculated [47].

Pignet Index $(\mathrm{PI})=\mathrm{S}-(\mathrm{W}+\mathrm{CC})$,

$\mathrm{S}$ - stature in $\mathrm{cm}$; $\mathrm{W}$ - weight in kg; $\mathrm{C}$ - chest circumference in $\mathrm{cm}$.

Corpulence Index (CI) also known as Rohrer's Index (RI): $(\mathrm{CI})=\mathrm{W} / \mathrm{S}^{3}$,

$\mathrm{W}$ - weight in $\mathrm{kg} ; \mathrm{S}$ - stature in $\mathrm{cm}^{3}$.

Body Mass Index $(\mathrm{BMI})=\left(\mathrm{W} / \mathrm{S}^{2}\right)$,

$\mathrm{W}$ - weight in kg; $\mathrm{S}$ - stature in $\mathrm{cm}^{2}$.

Erisman Index (EI) or Chest Proportionality Index $(\mathrm{CPI})=\mathrm{CC}-\mathrm{S}^{2}$,

$\mathrm{CC}$ - chest circumference in $\mathrm{cm} ; \mathrm{S}$ - stature in $\mathrm{cm}^{2}$

The flexion muscle force $(\mathrm{kg})$ of the right and left hand was measured using the hand dynamometry method [48]. Then the force index was calculated, i.e. percentage of muscle strength to body weight.

To assess cardiovascular (CV) status in resting conditions were evaluated heart rate (cardiac rate), systolic (SP) and diastolic blood pressure (DP) (mmHg) [49].

To assess the state of the respiratory system, the vital capacity of the lungs (VC, l), respiration rate, Stange's test and Genchi's test were measured. Stange's test (c) was performed as follows: the subject in the standing position breathes in, then exhales deeply and again inhales, 80$90 \%$ of the maximum, the time for holding the breath is noted. In Genchi test (c) after a normal exhalation, the subject is holding his breath for as long as possible [47].

VC was measured with a portable spirometer and the vital index (VI) was calculated.

Vital Index $(\mathrm{VI})=\mathrm{VC} / \mathrm{W}$,

$\mathrm{VC}$ - vital capacity in $\mathrm{ml} ; \mathrm{W}$ - weight in $\mathrm{kg}[50]$.

Kerdo Index $(\mathrm{KI})=(1-\mathrm{DP} / \mathrm{HR}) \mathrm{x} 100$,

$\mathrm{DP}$ - diastolic pressure in mmHg; $\mathrm{HR}$ - heart rate in beats per minute [47].

Blood Circulation Efficiency Coefficient $(\mathrm{BCEC})=$ (SP - DP) x HR,

SP - systolic pressure in mmHg; DP - diastolic pressure; HR - heart rate in beats per minute [47].

Endurance Coefficient $(\mathrm{EC})=(10 \times \mathrm{HR}) / \mathrm{PP}$,

$\mathrm{HR}$ - heart rate in beats per minute; $\mathrm{PP}$ - pulse pressure e.g. systolic pressure in $\mathrm{mmHg}$ - diastolic pressure in $\mathrm{mmHg}$ [47].

Adaptive Capacity $(\mathrm{AC})=0,011 \times \mathrm{HR}+0,014 \times \mathrm{SP}$ $+0,008 \times \mathrm{DP}+0,09 \times \mathrm{W}-0,009 \times \mathrm{S}+0,014 \times \mathrm{A}-0,27$,

$\mathrm{HR}$ - heart rate in beats per minute; SP - systolic pressure; DP - diastolic pressure; $\mathrm{W}$ - weight; $\mathrm{S}$ - stature in cm; A - age in years [47].

To determine the physical preparedness, the level of development of the basic motor qualities was assessed (Program "Physical Culture") [51]. Young men practiced physical culture 2 times a week for 2 academic hours. The annual load (144 hours) was evenly distributed over semesters. The program included the following sections: athletics (42 hours), volleyball (28 hours), athletic gymnastics (42 hours), swimming (28 hours), offset (4 hours). Classes were conducted according to a typical structure: the introductory part $(15-20 \mathrm{~min})$, the main part (35-45 min), the final part (19-15 min). The introductory part consisted of complex of general development exercises, the main part - the exercises of the corresponding sections, the final part - the complex of breathing exercises and exercises developing flexibility.

At the end of each semester, the students passed examinations included testing of the basic physical qualities in the conditions of gym and stadium on the following exercises: running on 30 and $100 \mathrm{~m}$, long jump from the place, inclination from standing on the bench, flexing and extending the arms, hanging on the bar, the slopes from the supine position on the back, running on $1000 \mathrm{~m}$, running on $3000 \mathrm{~m}$.

Statistical analysis. The results of the research were subjected to statistical processing using parametric statistics methods in the licensed software package 
Microsoft Excel. Further, the indicators of descriptive statistics were calculated: the arithmetic mean (M), the standard error of the mean (m), which was expressed in the text and tables as $\mathrm{M} \pm \mathrm{m}$. The differences were estimated by the Student's criterion (t) for independent samples and the chi-square test, and considered them reliable at $\mathrm{p}$ $<0,05$ (in the text is indicated as "**").

\section{Results}

It was found out statistically significant differences on 11 items on the research of 28 indexes (Table 1). The table shows only statistically significant differences. In the study of physical development, we have not established differences in absolute indexes (mass, body length, etc.). Relative indicators have changed - weight-growth indexes. This indicates a tendency to increase the body weight of young men during the first year of training.

From the indicators of physical preparedness, the time spent on the bar decreased and the run time increased by $1000 \mathrm{~m}$. This indicates a deterioration in the physical preparedness of students during the first year of training. From the indicators of the functional state vital capacity of length and vital index decreased. The endurance factor, adaptive potential, diastolic blood pressure increased. This indicates a worsening of the functional state.

The study established a number of statistically significant differences in physical development, physical fitness, functional status of students in the process of adaptation to learning. Weight-and-growth indices, endurance factor, adaptation potential, diastolic blood pressure and running time on $1000 \mathrm{~m}$ increased. There was a decrease in the level of life, the vital index, and the time spent on the bar.

\section{Discussion}

Physical development. We have established differences in weight-growth indices, including BMI. Because weight-to-height indexes are recalculating relative indicators, statistically significant differences are more likely to appear in them.

This indicates a tendency to increase the body weight of young men during the first year of training (body weight in this period is normal). This trend was identified by us with the help of recalculation indicators (indexes). Our data on the increase in BMI for the year are consistent with the data on the increase in BMI in young men during the first year of training [4], in the first 1,5 years at the university [52], for the first semester [12]. In our study, the BMI changed by $1,09 \mathrm{~kg} / \mathrm{m}^{2}$, and in another study [52] - by $0,7 \mathrm{~kg} / \mathrm{m}^{2}$. In a study of Pribis P. et al. [17] BMI changes insignificantly. Also according to Zaccagni L. et al. [18] BMI is not an informative indicator.

Although we did not study the component composition of the body, the change in BMI is associated with an increase in fat mass. This is indirectly confirmed by the deterioration in the indicators of physical fitness.

Indexes are traditionally considered indicative indexes, so we suggest using them as screening tests in health monitoring.

Physical fitness. The results of our study are correlated with the data on the physical preparedness of first-year students of Chelyabinsk (Russia) [53], Sterlitamak (Russia) [54]. Our data on the decrease in the time of hanging on the bar and the increase in the running time on $1000 \mathrm{~m}$ are confirmed by the literature data [54]. The study [55] shows the ambiguity of high-speed, speedstrength qualities and endurance results. In the literature, it is suggested that the results of carpal dynamometry and long jump from the place [14], for estimating the state of the cardiorespiratory system - running at medium distances [56], the 5- and 15-minute run for estimation of aerobic capacity be considered as the most informative

Table 1. Statistically significant differences in indicators

\begin{tabular}{lllllll}
\hline \multirow{2}{*}{ Parameters } & \multicolumn{2}{c}{ Group 1 } & \multicolumn{3}{c}{ Group 2 } \\
& $\mathbf{n}$ & $\mathbf{M}$ & $\mathbf{m}$ & $\mathbf{n}$ & $\mathbf{M}$ & $\mathbf{m}$ \\
\hline Physical development & & & & & & \\
Erisman Index & 58 & 2,71 & 1,00 & 59 & $5,96^{*}$ & 1,00 \\
Rohrer's Index & 58 & 12,44 & 0,20 & 59 & $13,19^{*}$ & 0,26 \\
Pignet Index & 58 & 17,43 & 1,91 & 59 & $11,37^{*}$ & 2,02 \\
Body Mass Index & 58 & 21,89 & 0,33 & 60 & $22,98^{*}$ & 0,39 \\
Physical preparedness & & & & & & \\
1000 m, min & 50 & 3,56 & 0,07 & 52 & $3,79 *$ & 0,07 \\
Hanging on a bar, sec & 59 & 41,93 & 3,6 & 56 & $33,07^{*}$ & 2,23 \\
Functional state & & & & & & \\
Vital capacity of length, $\mathrm{ml}$ & 60 & 4091,67 & 89,92 & 64 & $3856,25^{*}$ & 70,43 \\
Vital index, ml/kg & 58 & 60,07 & 1,1 & 64 & $55,66^{*}$ & 0,94 \\
Endurance coefficient & 59 & 14,13 & 0,51 & 60 & $15,84^{*}$ & 0,5 \\
Adaptive capacity & 58 & 2,09 & 0,02 & 60 & $2,19 *$ & 0,04 \\
Diastolic blood pressure, $\mathrm{mmHg}$ & 60 & 66,12 & 1,4 & 64 & $70,19^{*}$ & 1,16 \\
\hline
\end{tabular}

Note: ${ }^{*}$ - the differences are reliable, $p<0,05$ 
for estimating the isokinetic force [ 57], to evaluate the strength qualities - a long jump from the place [58], to assess the state of the cardiorespiratory system - shuttle run on 20 meters [59].

Functional state and operability. Our data on the reduction of the vital capacity of length, vital index and increase in diastolic blood pressure are confirmed in the literature. Thus, a decrease in vital capacity of length and an increase in diastolic blood pressure is observed in young men who engaged in weightlifting [60]. In the process of adaptation, students have an increase in diastolic blood pressure [61] and a tendency to hypertension [62]. An increase in diastolic blood pressure is a prognostically unfavorable sign and should be taken into account when assessing the response to physical exertion. We compared the endurance factor and the adaptation potential with the norms [47]. The increase in these indicators indexes results in weakening of the cardiovascular system and the

\section{References}

1. Zakharova RN, Timofeeva AV, Mikhajlova AE, Timofeev LF. Assessment of the state of health of first-year students. Problemy social'noj gigieny, zdravookhraneniia $i$ istoriia mediciny, 2014;4:6-8. (in Russian)

2. Schmidt M, Glob J. Predictors of self-rated health and lifestyle behaviours in Swedish university students. Health Science, 2012; 4(4): 1-14. https://doi.org/10.5539/gjhs. $\mathrm{v} 4 \mathrm{n} 4 \mathrm{p} 1$

3. Deliens T, Clarys P, De Bourdeaudhuij I, Deforche B. Weight, socio-demographics, and health behaviour related correlates of academic performance in first year university students. Nutrition Journal, 2013; 12: 162. https://doi. org/10.1186/1475-2891-12-162

4. Pullman AW, Masters RC, Zalot LC, Carde LE, Saraiva MM, Dam YY, Randall Simpson JA, Duncan AM. Effect of the transition from high school to university on anthropometric and lifestyle variables in males. Applied Physiology, Nutrition, and Metabolism, 2009; 34(2): 162-171. https:// doi.org/10.1139/H09-007

5. Deforche B, Van Dyck D, Deliens T, De Bourdeaudhuij I. Changes in weight, physical activity, sedentary behaviour and dietary intake during the transition to higher education: a prospective study. International Journal of Behavioral Nutrition and Physical Activity, 2015; 12:16. https://doi. org/10.1186/s12966-015-0173-9

6. Sakharova OB, Kiku PF, Gorborukova TV. The impact of social and hygienic lifestyle factors on health status of students. Gigiena i Sanitariia, 2012; (6): 54-58.

7. Ermolaeva SV. Evaluation of the physical development and adaptation capacities of the body of schoolchildren in the Ulyanovsk region. Gigiena i Sanitariia. 2014; 4: 90-93.

8. Proskuryakova LA, Burnysheva TV. Assessment of morbidity, physical health of students and the formation of self-protective behavior. Problemy social'noj gigieny, zdravookhraneniia $i$ istorii mediciny, 2012;3:15-17. (in Russian)

9. Marakushin D, Chernobay L, Vasylieva O, Karmazina I. Intersystem integration in terms of the educational process in the initial courses of higher medical school. Georgian medical news, 2016; (256-257): 88-92.

10.Karpenko IuD. Dynamics of the functional state and adaptation processes in students. Gigiena $i$ sanitariia, tension of adaptation mechanisms. Probably, in this case, the adaptation is non-physiological.

In our opinion, the indicator indexes for the adaptation of young men to learning are those for which statistically significant differences and confirmation in the literature have been obtained.

\section{Conclusions}

1. The ambiguous dynamics is shown: the speedstrength qualities did not change, the endurance and the state of the cardio-respiratory system worsened.

2. We suggest to consider the indicator indexes of the process of adaptation of female students for training: BMI (physical development index), running on $1000 \mathrm{~m}$ (physical fitness indicator), endurance factor (functional status indicator)

\section{Conflict of interest}

The authors state that there is no conflict of interest.
2012;4:61-63. (in Russian)

11.Ramírez-Vélez R, Meneses-Echavez JF, González-Ruíz $\mathrm{K}$, Correa JE. Muscular fitness and cardiometabolic risk factors among Colombian young adults. Nutrición Hospitalaria, 2014; 30(4): 769-775. https://doi.org/10.3305/ nh.2014.30.4.7684

12.Deliens T, Clarys P, Van Hecke L, De Bourdeaudhuij I, Deforche $\mathrm{B}$ Changes in weight and body composition during the first semester at university. A prospective explanatory study. Appetite, 2013; 65: 111-116. https://doi.org/10.1016/j. appet.2013.01.024

13.Kaj M, Tékus É, Juhász I, Stomp K, Wilhelm M. Changes in physical fitness of Hungarian college students in the last fifteen years. Acta Biologica Hungarica, 2015; 66(3): 270281. https://doi.org/10.1556/018.66.2015.3.3

14.Artero EG, España-Romero $\mathrm{V}$, Castro-Piñero $\mathrm{J}$, Ruiz $\mathrm{J}$, Jiménez-Pavón D, Aparicio V, Gatto-Cardia M, Baena P, Vicente-Rodríguez G, Castillo MJ, Ortega FB. Criterionrelated validity of field-based muscular fitness tests in youth. Journal of Sports Medicine and Physical Fitness, 2012; 52(3): 263-272.

15.Esteban-Cornejo I, Tejero-González CM, Martinez-Gomez D, del-Campo J, González-Galo A, Padilla-Moledo C, Sallis $\mathrm{JF}$, Veiga OL. Independent and combined influence of the components of physical fitness on academic performance in youth.; UP \& DOWN Study Group. Pediatrics, 2014;165(2): 306-312. https://doi.org/10.1016/j.jpeds.2014.04.044

16.Mikhajlova SV, Kuzmichev IuG, Zhulin NV. Assessment of the functional state of students based on the results of the step test and Martinet-Kushelevsky test. Vestnik Zdorov'e i obrazovanie v XXI veke, 2016;12:36-38. (in Russian)

17.Pribis P, Burtnack CA, McKenzie SO, Thayer J. Trends in body fat, body mass index and physical fitness among male and female college students. Nutrients, 2010; 2(10): 10751085. https://doi.org/10.3390/nu2101075

18.Zaccagni L, Barbieri D, Gualdi-Russo E. Body composition and physical activity in Italian university students. Journal of Translational Medicine, 2014; 12: 120. https://doi. org/10.1186/1479-5876-12-120

19.Khudolii OM, Ivashchenko OV, Iermakov SS, Rumba OG. Computer simulation of Junior gymnasts' training process. Science of Gymnastics Journal, 2016;8(3):215-228.

20.Podrigalo LV, Iermakov SS, Jagiełł W. Special indices of 
body composition as a criterion of somatic development of martial arts practitioners. Arch Budo Sci Martial Art Extreme Sport 2017; 13: 5-12.

21.Jagiełło M, Iermakov SS, Nowiński M. Differentiation of the somatic composition of students physical education specialising in various sports. Archives of Budo Science of Martial Arts and Extreme Sports. 2017;13.

22.Kriventsova I, Iermakov S, Bartik P, Nosko M, Cynarski WJ. Optimization of student-fencers' tactical training. Ido Movement for Culture-Journal of Martial Arts Anthropology. 2017;17(3):21-30. https://doi.org/10.14589/ido.17.3.3

23. Arziutov G, Iermakov S, Bartik P, Nosko M, Cynarski WJ. The use of didactic laws in the teaching of the physical elements involved in judo techniques. Ido Movement for CultureJournal of Martial Arts Anthropology. 2016;16(4):21-30. https://doi.org/10.14589/ido.16.4.4

24.Doroshenko EY, Svatyev AV, Iermakov SS, Jagiełło W. The use of cardio training facilities in training 7-9 year old judo athletes. Archives of Budo Science of Martial Arts and Extreme Sports. 2017;13.

25. White MA, Mayer M, Vanderlind WM, Allswede D. Evaluation of a Behavioral Self-Care Intervention for Public Health Students. American Journal of Health Education. 2017 Oct 10;1-8. https://doi.org/10.1080/19325037.2017.1 369199

26.Jagiello W, Kruszewski A. Morphological diversification of competitors training Greco-Roman style of wrestling. Archives of Budo. 2009;5: 147-153.

27.Alonso-Palacio LM, Cepeda-Díaz J, Castillo-Riascos LL, Pérez MA, Vargas-Alonso A, Ricardo-Barreto C. Interculturality in the formation of health students: A Colombian experience. HORIZONTE SANITARIO, 16(3). https://doi.org/10.19136/hs.a16n3.1837

28. Osipov AY, Kudryavtsev MD, Iermakov SS, Jagiello W. Criteria for effective sports selection in judo schools - on example of sportsmanship's progress of young judo athletes in Russian Federation. Archives of Budo. 2017;13:179-186.

29. Osipov AY, Kudryavtsev MD, Iermakov SS, Jagiello W. Topics of doctoral and postdoctoral dissertations devoted to judo in period 2000-2016-the overall analysis of works of Russian experts. Archives of Budo. 2017;13:1-10.

30.Kozina ZL, Iermakov SS, Kuzmin VA, Kudryavtsev MD, Galimov GJ. Change of Cortisol and Insulin Content in Blood under Influence of Special Workability Recreation System for Students with High Motor Functioning Level. Research Journal of Pharmaceutical Biological and Chemical Sciences. 2016;7(2):1068-1077.

31.Zarebska A, Jastrzebski Z, Moska W, Leonska-Duniec A, Kaczmarczyk M, Sawczuk M, et al. The AGT Gene M235T Polymorphism and Response of Power-Related Variables to Aerobic Training. Journal of Sports Science and Medicine. 2016;15(4):616-24.

32.Kozina ZL, Iermakov SS, Kadutskaya LA, Sobyanin FI, Krzeminski M, Sobko IN, et al. Comparative characteristic of correlation between pulse subjective indicators of girl students' and school girls' reaction to physical load. Physical Education of Students. 2016;20(4):24-34. https://doi. org/10.15561/20755279.2016.0403

33.Gmiat A, Mieszkowski J, Prusik K, Prusik K, Kortas J, Kochanowicz A, et al. Changes in pro-inflammatory markers and leucine concentrations in response to Nordic Walking training combined with vitamin D supplementation in elderly women. Biogerontology 2017:1-14. https://doi.org/10.1007/ s10522-017-9694-8

34.Osipov AY, Kudryavtsev MD, Kramida IE, Iermakov SS, Kuzmin VA, Sidorov LK. Modern methodic of power cardio training in students' physical education. Physical Education of Students. 2016;20(6):34-39. https://doi. org/10.15561/20755279.2016.0604

35.Kopeikina EN, Drogomeretsky VV, Kondakov VL, Kovaleva MV, Iermakov SS. Modification of Harvard step-test for assessment of students' with health problems functional potentials. Physical Education of Students. 2016;20(4):4450. https://doi.org/10.15561/20755279.2016.0405

36.Kortas J, Prusik K, Flis D, Prusik K, Ziemann E, Leaver $\mathrm{N}$, et al. Re: Possible effect of decreased insulin resistance on ferritin levels after Nordic Walking training. Clinical Interventions in Aging, 2016;11:150-151.

37.Druz VA, Iermakov SS, Nosko MO, Shesterova LY, Novitskaya NA. The problems of students' physical training individualization.PedagogicsPsychologyMedical-Biological Problems of Physical Training and Sports. 2017;21(2):5159. https://doi.org/10.15561/18189172.2017.0201

38.Hickey EL, Dumke EK, Ballentine RL, Brown BL. Prospective health students' perceptions of the pharmacist role in the interprofessional team. Journal of Interprofessional Care. 2017 Oct $23 ; 1-4$. https://doi.org/10.1080/13561820.20 17.1381671

39.Ziolkowski A, Zubrzycki I, Blachnio A, Drobnik P, Zaranska $\mathrm{B}$, Moska W. Influence of sport activity on satisfaction with life and sense of coherence among physically disabled people. Baltic Journal of Health and Physical Activity. 2016;8(4):109-16.

40.Radziminska A, Weber-Rajek M, Lewandowska J, LulinskaKuklik E, Straczynska A, Moska W. Evaluation of the efficacy of low level laser therapy and cryotherapy in the treatment of gonarthrosis. Baltic Journal of Health and Physical Activity. 2016;8(2):87-95.

41.Kriventsova I, Pashkevych S, Iermakov S, Bartík P, Michal J, Nosko M, Yermakova T. Fitness - aerobic training of 15 - 17 years' age girl students, who have significant risk of deviations in backbone functional state. Journal of Human Sport and Exercise, 2017;12(4), 1289-1297. https://doi. org/10.14198/jhse.2017.124.15

42.Jastrzebski Z, Zychowska M, Jastrzebska M, Prusik K, Prusik K, Kortas J, et al. Changes in blood morphology and chosen biochemical parameters in ultra-marathon runners during a $100-\mathrm{km}$ run in relation to the age and speed of runners. International Journal of Occupational Medicine and Environmental Health. 2016;29(5):801-14. https://doi. org/ 10.13075/ijomeh.1896.00610

43.Kalina RM, Jagiello W, Chodala A. The result of "testing fights in a vertical posture" as a criterion of talent for combat sports and self-defence - secondary validation (part II: the accuracy). Archives of Budo Science of Martial Arts and Extreme Sports. 2016;12.

44.Annear MJ, Elliott K-EJ, Tierney LT, Lea EJ, Robinson A. "Bringing the outside world in": Enriching social connection through health student placements in a teaching aged care facility. Health Expectations. 2017 Oct;20(5):1154-62. https://doi.org/10.1111/hex.12561

45.Jones GH. Mental health student nurses' satisfaction with problem-based learning: a qualitative study. The Journal of Mental Health Training, Education and Practice. 2017 Mar 13;12(2):77-89.

46.Marfell-Jones MJ, Stewart AD, de Ridder JH. International standards for anthropometric assessment. Wellington, New Zealand: International Society for the Advancement of Kinanthropometry; 2012.

47.Tulyakova OV. Human ecology. Kirov; 2010. (in Russian) 48.Muscle Strength Procedures Manual. National Health and Nutrition Examination Survey; 2011. 
49.Pulse and Blood Pressure Procedures for Household Interviewers. National Health and Nutrition Examination Survey; 1993.

50.Moore VC. Spirometry: step by step. Breathe, 2012; 8: 232240. https://doi.org/10.1183/20734735.0021711

51.Fedoseev VN. An approximate program of the discipline «Physical Culture». Novosibirsk; 2014. (in Russian)

52.Deliens T, Deforche B, De Bourdeaudhuij I, Clarys P. Changes in weight, body composition and physical fitness after 1.5 years at university. European Journal of Clinical Nutrition, 2015; 69(12):1318-1322. https://doi.org/10.1038/ ejen.2015.79

53.Ushakov AS, Nenasheva AV, Kleshchenkova NE. Comparative analysis of indicators of physical readiness of 11th grade students and 1st year students // Chelovek. Sport. Medicina, 2014;2:114-118. (in Russian)

54.Ulyanbaeva RG. An integrated approach to the formation of health culture of a student. Teoriia i praktika fizicheskoj kul'tury, 2007;5:49-51. (in Russian)

55.Artemenkov AA. Physical development and physical readiness of students of ecologically unfavorable city. Ekologiia cheloveka, 2012;4:39-44. (in Russian)

56.Mayorga-Vega D, Bocanegra-Parrilla R, Ornelas M, Viciana J. Criterion-Related Validity of the Distance- and TimeBased Walk/Run Field Tests for Estimating Cardiorespiratory Fitness: A Systematic Review and Meta-Analysis. PLoS One, 2016; 11(3): e0151671. https://doi.org/10.1371/journal. pone. 0151671
57.MacNaughton L, Croft R, Pennicott J, Long T. The 5 and 15 minute runs as predictors of aerobic capacity in high school students. The Journal of Sports Medicine and Physical Fitness. 1990; 30(1): 24-28.

58.Castro-Piñero J, Ortega FB, Artero EG, Girela-Rejón MJ, Mora J, Sjöström M, Ruiz JR. Assessing muscular strength in youth: usefulness of standing long jump as a general index of muscular fitness. Journal of Strength and Conditioning Research, 2010; 24(7): 1810-1817. https://doi.org/10.1519/ JSC.0b013e3181ddb03d

59.Domone S, Mann S, Sandercock G, Wade M, Beedie C. A Method by Which to Assess the Scalability of FieldBased Fitness Tests of Cardiorespiratory Fitness Among Schoolchildren. Sports Medicine, 2016; 46(12):1819-1831. https://doi.org/10.1007/s40279-016-0553-6

60.Tarasova LV, Korzhenevskij AN, Vorob’ev AV, Khudadov NA, Malinovskij SV. Assessment of external breathing of qualified weightlifters. Vestnik sportivnoj nauki, 2013;4: 5053. (in Russian)

61.Sukhanova IV, Maksimov AL. Modern trends in the physical development and the state of the cardiovascular system in young men of the city of Magadan. Gigiena i Sanitariia, 2015; 94(3): 83-86.

62.Kretova IG, Beliaeva OV, Shiriaeva OI, Komarova MV, Chigarina SE, Koscova EA. Influence of social and psychological factors on the formation of health of students in the period of study at a higher educational institution. Gigiena i sanitariia, 2014;4:85-90. (in Russian)

Information about the authors:

Tulyakova O.V. (Corresponding author); http://orcid.org/0000-0002-2095-4309; ov tulyakova@vyatsu.ru; Department of Students' Research Work, Vyatka State University; Moskovsky str., 36, Kirov, 610000, Russia.

Avdeeva M.S.; http://orcid.org/0000-0002-6760-7347; usr11253@vyatsu.ru; Department of Physical Education, Vyatka State University; Moskovsky str., 36, Kirov, 610000, Russia.

Cite this article as: Tulyakova OV, Avdeeva MS. Informative indices of physical and functional state of young men during the process of adaptation to learning. Pedagogics, psychology, medical-biological problems of physical training and sports, 2018;22(1):44-49. doi:10.15561/18189172.2018.0106

The electronic version of this article is the complete one and can be found online at: http://www.sportpedagogy.org.ua/index.php/PPS/issue/archive

This is an Open Access article distributed under the terms of the Creative Commons Attribution License, which permits unrestricted use, distribution, and reproduction in any medium, provided the original work is properly cited (http://creativecommons.org/licenses/by/4.0/deed.en).

Received: 15.09 .2017

Accepted: 08.10.2017; Published: 26.02.2018 